\title{
ORDENAR AS PAIXÕES: RECONHECIMENTO E SOCIABILIDADE NO EMÍLIO DE ROUSSEAU - SEGUNDA PARTE
}

\author{
Thomaz Kawauche ${ }^{1}$
}

\begin{abstract}
Resumo:
Este artigo recupera o problema do reconhecimento no quadro teórico do artigo anterior e prossegue examinando, na leitura de Emílio, ou Da educação, o princípio da ordem das paixões como condição de sociabilidade. Dessa vez, o comentário procura esclarecer a ideia de reconhecimento segundo Rousseau com base em dois pontos fundamentais de Emílio, a saber, o modelo de espetáculo para as cenas pedagógicas e o princípio da amizade para formação do juízo moral. No tocante às cenas, Rousseau recoloca o princípio da "educação negativa" com base na tese da Carta a d'Alembert sobre os espetáculos, a saber, que as cenas teatrais são incapazes de modificar os costumes, uma vez que, diante do "quadro das paixões", a "cena em geral" não produz virtude, mas apenas reforça as inclinações já existentes no espírito do espectador. Em relação à amizade, Rousseau lida com o problema do amor-próprio ponderando que, embora as relações entre amigos não sejam suficientes para anular o conflito de interesses inerente à luta por reconhecimento, o arranjo social engendrado por elas apresenta um ordenamento satisfatório do ponto de vista da boa ordem das paixões.
\end{abstract}

Palavras-chave: Educação. Moral. Reconhecimento. Sociabilidade. Teatro.

\section{TO ORDER THE PASSIONS: RECOGNITION AND SOCIABILITY IN ROUSSEAU'S EMILE - SECOND PART}

\begin{abstract}
:
This article recovers the problem of recognition in the theoretical framework of the previous text and, in reading Émile, ou de l'éducation, goes on to examine the order of passions principle as condition of sociability. This time, the commentary seeks to clarify the idea of recognition according to Rousseau based on two fundamental points of Émile, namely, the theater model for the pedagogical scenes and the principle of friendship for moral judgment formation. With regard to the scenes, Rousseau replaces the "negative education" principle based on the thesis of Lettre à d'Alembert sur les spectacles, namely, that the theatrical scenes are unable to change the customs, since, in the face of the "frame of passions", the "scene in general" does not produce virtue, but only reinforces the inclinations already existing in the spirit of spectator. In relation to friendship, Rousseau deals with the problem of self-love by considering that, although relationships among friends are not enough to cancel the conflict of interests inherent in the struggle for recognition, the social arrangement engendered by them presents a satisfactory order from the point of view of the good order of the passions.
\end{abstract}

Keywords: Education. Morals. Recognition. Sociability. Theater.

Em sequência ao meu texto publicado neste periódico (cf. KAWAUCHE, 2019), o presente artigo apresenta mais algumas conclusões da pesquisa que realizo sobre Rousseau e as ciências modernas. Porém, antes de entrar na matéria atual, faço uma recapitulação do artigo anterior: ali expus o arcabouço teórico da análise esforçando-me para formular, no quadro da educação moral de Emílio, o problema da ordem das paixões ligadas ao amor-

1 Doutor em Filosofia pela USP, Professor Visitante no Departamento de Filosofia da UNIFESP, membro fundador da Associação Brasileira de Estudos do Século XVIII (ABES XVIII) e autor do livro Religião $e$ política em Rousseau: o conceito de religião civil (São Paulo: Humanitas \& FAPESP, 2013). E-mail: kawauche@unifesp.br 
próprio; para tanto, propus a hipótese da relação entre estima pública e consciência como alicerce teórico sobre o qual Rousseau elabora um modelo de sociabilidade. Em linhas gerais, busquei comentar a seguinte tese: para Rousseau, "ordenar as paixões humanas" diz respeito não apenas a uma estratégia profilática retentora das paixões maléficas que necessariamente surgem junto com o amor-próprio ao longo do desenvolvimento do jovem aluno, mas também a uma tentativa para se compreender a relação entre moral e política do ponto de vista daquilo que, na literatura da crítica social contemporânea, conhecemos por teoria do reconhecimento ${ }^{2}$. A reflexão geral apresentada no texto procurou explicitar a relevância dos modelos de racionalidade da medicina do século XVIII para que Rousseau pudesse inferir a ideia de reconhecimento com base na complexa relação entre consciência e estima. O resultado, longe de resumir-se a uma única tese, consiste no esboço de uma oficina de trabalho onde novas hipóteses ligadas ao preceito de "ordenar as paixões" podem ser inferidas e examinadas. Neste artigo, com o intuito de incitar o debate em torno às minhas elaborações preambulares no terreno construído, proponho-me investigar alguns desdobramentos da relação entre estima e reconhecimento no interior do quadro teórico em questão; o comentário levará em conta dois pontos concernentes à "ordem das paixões" que me parecem estruturantes do Emílio como um todo: (1) o modelo do espetáculo para as cenas pedagógicas e (2) a ideia de amizade para formação do juízo moral.

\section{As paixões e o modelo do teatro}

Podemos compreender a ideia de reconhecimento na obra de Rousseau comparando o sistema moral exposto em Emílio e a imagem do teatro como "quadro das paixões" na Carta a d'Alembert sobre os espetáculos. Antes de mais nada, convém recordar que Emílio é educado através das chamadas "cenas pedagógicas" e que, tanto na Carta quanto no Emílio, a questão examinada poderia ser postulada nos seguintes termos: como fomentar atos de virtude a partir dos efeitos da cena teatral sobre as paixões? Examinemos a colocação dessa pergunta primeiro no Emílio e depois na Carta.

Com o intuito de persuadir Emílio no momento da adolescência, o educador evoca

2 Veja-se a longa nota de balanço bibliográfico da primeira parte desse artigo. Menciono apenas o ensaio fundamental de Axel Honneth, "Abismos do reconhecimento" (original publicado em 2012), no qual Rousseau é chamado de "o fundador de toda a tradição da teoria do reconhecimento" (HONNETH, 2013, p. 566).

\begin{tabular}{|l|l|l|l|l|}
\hline Rovista Dialectus & Ano 9 & n. 17 & Maio-Agosto 2020 & p.271-292 \\
\hline
\end{tabular}


as paixões do aluno. Lembremos que, para Rousseau, a educação "segundo a natureza" é aquela que adia o desenvolvimento da razão com vistas a minimizar os efeitos da opinião pública sobre o desenvolvimento cognitivo da criança. Assim, os ensinamentos não são dados em forma de discursos, mas como cenas de teatro, pois estas comunicam certas lições de moral sem exigir de Emílio muita capacidade de raciocínio. Entretanto, mais do que priorizar a paixão frente à razão, as cenas são apresentadas numa série calculada, ou seja, a sequência das cenas às quais Emílio assistirá é ordenada com método. No artigo "Dos jogos de teatro no pensamento pedagógico e político de Rousseau", Luiz Roberto Salinas Fortes analisa o modelo do "teatro pedagógico" em Emílio e afirma que a metáfora do teatro nas "cenas" dessa obra diz respeito "ao nível primeiro da 'composição' global do Livro" (SALINAS FORTES, 1979, p. 83); de acordo com o comentador brasileiro, Rousseau elabora Emílio refletindo sobre o problema dos espetáculos "de maneira inteiramente 'sistemática", tendo em vista "um esquema de pensamento bastante explícito" orientado pelo "paradigma o teatro" (Ibid., p. 80, 81 e 83). ${ }^{3}$ Com efeito, são os espetáculos das "cenas pedagógicas" que, em maior ou menor grau, impressionam Emílio a ponto de, em alguma medida, mudar a configuração dos afetos de sua alma, com a vantagem de não se recorrer a professores arrogantes que só produziriam "pequenos doutores", ou seja, alunos tagarelas e presunçosos cujos conhecimentos seriam duvidosos por não serem produzidos a partir da experiência e da observação deles mesmos. O método das cenas substitui a pessoa do mestre, neutralizando assim o personalismo na prática do ensino e os vícios inerentes à tendência que as crianças têm de imitar os adultos.

A cena do espetáculo imprime algo no espírito do espectador, e essa impressão altera a ordem dos sentimentos, de modo que os afetos mudam juntamente com o rearranjo do espírito; e o fato de haver uma sequência de impressões ordenadas com método torna possível que a ordem das cenas estabeleça na constituição do aluno uma certa ordem das paixões. Lembremos, por exemplo, da lição sobre a propriedade no livro II: com a plantação de favas espetacularmente arruinada pelo jardineiro Robert, Emílio sente em sua própria pessoa (no sentido lockiano de pessoa, em referência à expansão do eu mediante o trabalho do corpo) a injustiça nas relações com os outros que não conhece e, assim, no conflito interno envolvendo

\footnotetext{
Nunca é demais lembrar que, no Brasil, há duas grandes referências para o estudo desse tema em Rousseau: o ensaio "Gênese e estrutura dos espetáculos", de Bento Prado Jr. (1975), e a tese de livre-docência Paradoxo do espetáculo: política e poética em Rousseau, de Luiz Roberto Salinas Fortes (defendida em 1983 e publicada em 1997). O mais recente trabalho de fôlego no tema dos espetáculos é a tese doutoral de Rafael de Araújo e Viana Leite, O teatro em Rousseau: entre o universal e o particular (2018).
}

\begin{tabular}{|c|c|c|c|c|}
\hline Rovista Dialectus & Ano 9 & n. 17 & Maio - Agosto 2020 & p.271-292 \\
\hline
\end{tabular}


projeções diferentes de seu próprio $e u$, aprende sobre as relações de justiça que dizem respeito à ocupação de terras. Somente após ter se apropriado da noção de identidade pessoal é que a criança poderá entender as relações interpessoais e os constrangimentos da coletividade sobre o individuo do ponto de vista da justiça, como vemos no episódio do prestidigitador que pratica o truque do pato de cera no livro III. Nesse caso, Emílio se vê como espetáculo de chacota e, por essa humilhação pública, tem a ordem de seus afetos alterada: o principal efeito é que ele perderá o interesse de exibir-se vaidosamente em público. Se a ordem dessas duas cenas fosse invertida, Emílio tenderia a valorizar mais o barulho da opinião pública do que o sentimento de justiça que percebe silenciosamente em seu $e u$ interior. Dito de outro modo, a ordem na formação dos sentimentos afeta necessariamente a formação da ordem das paixões. Passemos agora à Carta.

A estratégia de Rousseau na Carta a d'Alembert sobre os espetáculos é bem conhecida: demonstrar que a questão dos efeitos da cena está mal colocada, pois, em matéria de teatro, os espectadores não se comovem pelo que é exibido no palco como útil aos homens, mas apenas por aquilo que lhes parece aprazível; dito de outro modo, a crítica de nosso autor aos supostos benefícios pedagógicos do teatro recoloca o problema dos espetáculos no viés realista de um retrato dos homens tais como são na experiência histórica. O objetivo de Rousseau na Carta consiste em persuadir d'Alembert acerca da inutilidade dos espetáculos sobre os princípios de conduta mostrando que, nos imbricamentos entre os espetáculos e a ordem moral, as normas postuladas pela razão contam pouco ou quase nada, haja vista a ineficácia da razão na tarefa de promover mudanças perduráveis nos costumes pela mera exibição da virtude sob as luzes do palco. Em última instância (eis o alcance máximo dos efeitos morais do teatro), a plateia só reconhece o bom exemplo dos personagens nos casos em que o presumido ensino moral se reduz à bajulação. É por isso que, aos olhos de Rousseau, d'Alembert manifesta uma confiança injustificável na razão ao declarar, no verbete "Genebra" da Enciclopédia, que "as representações teatrais formariam o gosto dos cidadãos e lhes dariam uma fineza de tato, uma delicadeza de sentimento que dificilmente poderia ser adquirida sem esse auxílio" (D'ALEMBERT, 2015, p. 158). A fórmula lapidar da tese contrária com a qual Rousseau refuta d'Alembert encontra-se na seguinte passagem da Carta:

A cena, em geral, é um quadro das paixões humanas, cujo original se encontra em todos os corações; mas, se o pintor não tivesse o cuidado de favorecer essas paixões, os espectadores logo ficariam aborrecidos e não desejariam mais ver-se sob um aspecto que teria feito com que desprezassem a si mesmos. Se a algumas delas ele empresta cores odiosas, é somente àquelas que não são gerais e que

\begin{tabular}{|c|c|c|c|c|}
\hline Q Rovista Oialectus & Ano 9 & n. 17 & Maio - Agosto 2020 & p.271-292 \\
\hline
\end{tabular}


naturalmente odiamos. Assim, também com relação a isso, o autor apenas segue o sentimento do público; e então essas paixões de refugo são sempre empregadas para fazer valer outras, senão mais legítimas, ao menos mais ao gosto dos espectadores. Só a razão não serve para nada na cena. Um homem sem paixões, ou que sempre as dominasse, não poderia interessar a ninguém [...]. (ROUSSEAU, 2020, pp. 372-373) ${ }^{4}$.

Sem entrarmos no mérito dos estudos de especialistas ${ }^{5}$, concentremo-nos em nosso propósito. Podemos seguramente dizer que todos os escrúpulos do educador de Emílio concernentes ao primado das paixões sobre a razão podem ser justificados pelo trecho da Carta acima citado. Contudo, não obstante a importância da tese da Carta na antropologia de Emílio, devemos notar que os fundamentos da questão são anteriores à querela em torno ao teatro de Genebra. ${ }^{6}$ No "sistema de Rousseau" compreendido pelo conjunto de seus escritos sobre moral e política, a imagem do "quadro das paixões" corresponde a um esquema das faculdades humanas em sentido abrangente; por esse motivo, do ponto de vista do método rousseauniano, tal esquema nos remete aos princípios do sistema; isto é, ao esquema do homem natural introduzido na "ciência do homem" do Discurso sobre a origem da desigualdade - homem este cujo progresso hipotético é ordenado pela precedência das paixões em relação à faculdade racional:

Digam o que disserem os moralistas, o entendimento humano deve muito às paixões, que, segundo uma opinião geral, lhe devem muito também: é pela sua atividade que nossa razão se aperfeiçoa; só buscamos conhecer por desejarmos usufruir, não sendo possível conceber por que aquele que não tivesse desejos nem temores se daria ao trabalho de raciocinar. (ROUSSEAU, 1964, p. 143).

Então, se analisarmos conjuntamente o Discurso, a Carta e o Emílio, veremos que, na história do aluno imaginário de Rousseau, a emergência tardia da razão na série de cenas pedagógicas se justifica pela máxima que orienta a crítica aos espetáculos na Carta do ponto de vista da moral: "a razão não produz nenhum efeito no teatro" (ROUSSEAU, 2020, p. 376); isso porque, na perspectiva da "ciência do homem" do Discurso, os efeitos buscados são

4 Cito a excelente tradução da Carta a d'Alembert assinada por Fabio Yasoshima e publicada pela Ubu em 2020 no volume Rousseau: escritos sobre a política e as artes. Essa versão deve substituir as anteriores, de Lourdes Santos Machado (Globo, 1958) e Roberto Leal Ferreira (Unicamp, 1993).

5 Vale a pena citar Franklin de Mattos quando afirma, no melhor comentário publicado até hoje sobre a Carta, que a releitura que Rousseau faz das teorias da tragédia e da comédia relaciona a "psicologia" exposta no Emílio e a "estética" do século XVIII. Grosso modo, Mattos demonstra que um dos aspectos originais da Carta está em subverter o problema da "consciência estética" tal como formulado naquela época: segundo Rousseau, é a natureza humana que deve ser adotada como fio condutor para decifrar as obras de arte, e não o inverso (cf. MATTOS, p. 22). Parece-me que o mesmo pode ser afirmado acerca das obras de arte no registro da educação, e é disso que se trata na análise dessa sessão do artigo.

6 Dos estudos recentes sobre a antropologia de Rousseau, o esforço mais abrangente foi feito por Mauro Dela Bandera Arco Jr., A origem da alteração e a alteração de origem: antropologias de Rousseau (2018).

\begin{tabular}{|l|l|l|l|l|}
\hline Revista Dialectus & Ano 9 & n. 17 & Maio-Agosto 2020 & p.271-292 \\
\hline
\end{tabular}


aqueles ligados originalmente às paixões anteriores à razão: estamos falando dos dois móbiles do homem no hipotético estado de natureza, a saber, o amor de si e a piedade natural (ROUSSEAU, 1964, p. 126). De fato, assim como afirma na Carta, também em Emílio Rousseau se refere aos efeitos sociais dos espetáculos ligados às paixões naturais, adotando na descrição da natureza humana um esquema de faculdades semelhante ao do Discurso sobre a origem da desigualdade. Eis o "espírito do método" que anima a seguinte frase encontrada no livro IV de Emílio: "Só se conquista as paixões pelas paixões; é por meio do império delas que precisamos combater-lhes a tirania, e é sempre da própria natureza que é preciso tirar os instrumentos próprios para regulá-la" (ROUSSEAU, 1969, p. 654)..$^{7}$ Podemos daí entender que, nas cenas pedagógicas em Emílio, as paixões desempenham um papel não menos importante que a grande protagonista da cena filosófica no Século das Luzes - a razão.

\section{O quadro das paixões e seus limites}

Deixemos de lado, agora, os pormenores da "ciência do homem" de Rousseau para não perdermos de vista o escopo deste artigo: nosso foco é a crítica da alçada dos espetáculos teatrais no tocante à ordem moral em Emílio. Ao tomar como objeto o esquema de faculdades implicado no "quadro das paixões" da Carta, a arte do educador pode, na melhor das hipóteses, reforçar as boas inclinações da criança, permanecendo em qualquer circunstância incapaz de nela produzir interesse pelo bem ou aversão pelo mal de modo perene. E isso, tanto no âmbito da moral quanto no da política. Se admitirmos que o Emílio e o Contrato social são textos complementares (pois, para Rousseau, moral e política são inseparáveis ${ }^{8}$ ), não nos espantaremos com o fato de haver semelhança entre o "quadro das

7 Embora critique o "espírito de sistema" dos filósofos, Rousseau fala em "espírito do método" quanto trata da ordem no surgimento das paixões de Emílio (cf. ROUSSEAU, 1969, p. 510). Vale observar ainda que Rousseau não recusa a razão em favor das paixões (se assim fosse, ele seria um irracionalista); o que ele defende é o aperfeiçoamento da razão por meio das paixões, e não o inverso, como na experiência do pensamento da estátua de Condillac no Tratado das sensações, segundo a qual as sensações (e as paixões delas derivadas) precedem o engendramento da faculdade racional. Essa é a boa ordem no progresso do espírito humano segundo Rousseau. A vantagem em se adotar tal esquema antropológico é dupla: uma maior simplicidade na hipótese inicial do indivíduo em estado de natureza (trata-se de uma virtude do ponto de vista das ciências empíricas) e permite mais inferências no estudo dos fenômenos sociais. Basta lembrarmos que, na comparação entre o estado de natureza de Hobbes e de Rousseau, o homem natural do Discurso sobre a desigualdade é uma hipótese mais simples do que aquele do Leviatã, pois a capacidade de antecipar o futuro que acaba produzindo o estado de guerra de todos contra todos é decorrência lógica de mudanças nas relações entre o indivíduo e seu entorno, e não um dado da natureza humana; ou seja, a teoria do estado de natureza de Rousseau explica a de Hobbes, sendo portanto mais abrangente em termos das inferências que dela decorrem.

8 "É preciso estudar a sociedade pelos homens e os homens pela sociedade: aqueles que quiserem tratar

\begin{tabular}{|l|l|l|l|l|}
\hline Revista Dialectus & Ano 9 & n. 17 & Maio-Agosto 2020 & p.271-292 \\
\hline
\end{tabular}


paixões" da Carta e o esquema antropológico do Contrato segundo o qual Rousseau enfatiza o interesse como móbil das ações dos indivíduos; seria oportuno apenas pontuar que, no Contrato, a questão diz respeito ao legislador. De fato, quando examinada do ponto de vista do devir histórico, a obra-prima da arte da legislação, que é a convergência das vontades individuais, tende a se fragmentar numa pluralidade conflituosa de interesses particulares, e é exatamente aí que reside o embaraço. Examinemos essa dificuldade.

Ainda que tais interesses plurais e conflitantes não sejam necessariamente viciosos, a mera comparação entre os indivíduos interessados produz desejo de preferência (essa é a lição do momento do canto e da dança no Discurso) - assim, na melhor das hipóteses, as pessoas de bem não apenas serão refratárias a qualquer tipo de reforma em seus interesses, como ainda só estarão dispostas a ouvir os discursos de adulação (lembremos do que Rousseau diz no cap. 20 do Ensaio sobre a origem das línguas acerca dos predicadores que se fadigam inutilmente com sermões ao povo). A cena do pato de cera no livro III de Emílio é um exemplo significativo dos perigos da adulação ao longo dos progressos de Emílio; nunca será demais notar que a "cura" da vaidade naquele episódio ocorre somente porque a humilhação pública torna desinteressante o exibicionismo da criança, o que não significa que a criança deixou de ser vaidosa, pois afinal, o amor-próprio não desaparece. De forma similar, o previdente legislador do Contrato não pode curar a cegueira política do povo, mas pode traduzir na linguagem das paixões vulgares as grandes máximas que o povo não consegue entender (os dogmas da religião, por exemplo) servindo-se como "guia" da "multidão cega". Tanto o educador de Emílio quanto o legislador do Contrato parecem enganar seus conduzidos, mas essa condução forçada se justifica por acontecer necessariamente no registro imprevisível da história, onde tudo de bom ou de mal pode acontecer. A fim de evitar os desvios acidentais causados pelas paixões ao longo do devir histórico, a "inteligência superior" impõe-se como "guia seguro"; ambas as imagens, a do povo cego e a da criança ingênua, justificam a necessidade da tutela provisória, haja vista a incapacidade de compreensão das "sãs máximas" antes que a razão entre em cena, quer na perspectiva da educação pública, quer no âmbito da educação doméstica. ${ }^{9}$ A ordem das

separadamente a política e a moral nunca entenderão nada de nenhuma das duas" (ROUSSEAU, 1969, p. 524).

9 Há uma afirmação em nota no livro III de Emílio que, de um ponto de vista metodológico, é emblemática nessa questão: "adotei como lei inviolável nada exigir dele cuja razão não estivesse a seu alcance" (ROUSSEAU, 1969, p. 465, nota). Sobre a relação entre educação pública e educação doméstica, vale a pena ler os textos de Maria de Fátima Simões Francisco, em particular, FRANCISCO, 2010).

\begin{tabular}{|l|l|l|l|l|}
\hline Gevista Qialectus & Ano 9 & n. 17 & Maio - Agosto 2020 & p.271-292 \\
\hline
\end{tabular}


paixões e a ordem histórica são problemas correlatos em Emílio. Vamos recordar que a formação do aluno imaginário de Rousseau depende não apenas do educador, mas também das condições materiais que balizam sua própria formação ao longo da história, o que leva o genebrino a reconhecer tal obra de arte como "impossível”: "Uma vez que a educação é uma arte, é quase impossível que ela tenha êxito, já que o concurso necessário a seu sucesso não depende de ninguém" (ROUSSEAU, 1969, p. 247).

Em todos os exemplos, o erro está ligado à desordem que o devir histórico causa ao arranjo das paixões e, no entanto, é a própria historicidade da ordem das paixões que oferece algum tipo de esperança pela introdução de hábitos salutares, uma vez que "o hábito só se adquire com o tempo" (ROUSSEAU, 1969, p. 475). Com efeito, as intervenções da educação "segundo a natureza" vertidas para a linguagem dos espetáculos circunscrevem a arte do educador à tarefa de preservar a bondade natural dos seres humanos e, em sentido inverso, desacelerar o surgimento das tendências malignas. O legislador e o educador são, antes de tudo, alegorias do médico que, embora intervenha sobre o paciente com arte, nem por isso deixa de contar com a natureza para que os efeitos da arte médica sejam benéficos. Assim como na medicina hipocrática, a cura não acontece imediatamente como se dependesse apenas da arte médica, mas necessita do transcurso de um certo intervalo temporal, pois, como declara a máxima da tradição, o médico em última instância é a própria natureza:

Se quiserdes colocar ordem e regra nas paixões nascentes, ampliai o espaço durante o qual elas se desenvolvem, a fim de que tenham tempo para se arranjarem na medida em que nascem. Então, não é mais o homem que as ordena, é a própria natureza; vosso zelo consiste apenas em deixá-la ajeitar seu trabalho. (ROUSSEAU, 1969, p. 500).

A analogia com a arte do educador é clara: o artifício do médico é tão mais perfeito quanto melhor se mostrar "segundo a natureza", de modo a instituir uma "segunda natureza", ou seja, um simulacro da ordem natural que, enquanto obra de arte necessariamente imperfeita, portanto -, é acessível ao entendimento humano. É essa natureza "desnaturada" que está no horizonte de um outro princípio das cenas pedagógicas: a “educação negativa", definida por Rousseau como estratégia profilática que consiste "não em ensinar a virtude ou a verdade, mas em proteger o coração contra o vício e o espírito contra o erro" (ROUSSEAU, 1969, p. 346). Não há outra justificativa para que o gosto pelas ciências deva preceder o aprendizado delas: "Não se trata de ensinar-lhe as ciências, mas de dar-lhe gosto para amá-las e, quando esse gosto estiver melhor desenvolvido, métodos para aprendê-

\begin{tabular}{|c|c|c|c|c|}
\hline Qovista Dialectus & Ano 9 & n. 17 & Maio - Agosto 2020 & p.271-292 \\
\hline
\end{tabular}


las. Está aí, muito certamente, um princípio fundamental de toda boa educação" (Rousseau, 1969, p. 436, meus os itálicos). Observe-se que a "educação negativa” se justifica porque o modelo antropológico do Discurso proíbe qualquer tipo de otimismo inspirado por teorias propositivas de educação tradicional: a intervenção é negativa porque nega o mal sem propor nenhum bem explicitamente, ela protege dos vícios e dos erros antes de afirmar positivamente o bem, admitindo como único bem absoluto a bondade natural do ser humano. Assim como na Carta, não é possível ao educador de Emílio fabricar a virtude. Isso posto, podemos então dizer que a crítica ao teatro da Carta a d'Alembert sobre os espetáculos se coaduna à "educação negativa" de Emílio, e que em ambos os escritos o princípio da bondade natural do homem se manifesta na prática como reforma dos costumes - e isso, na melhor das hipóteses, uma vez que, na realidade histórica dos homens "tais como são", o cenário em geral é bem pior do que aquele idealizado no plano do dever-ser.

O esquema das faculdades no "quadro das paixões" da Carta nos leva ainda a uma questão de história da medicina. De fato, as conclusões parciais de nosso estudo sobre Rousseau e as ciências modernas sugerem outra aproximação: assim como se verifica no teatro pedagógico de Emílio, a gênese e a estrutura da cena na Carta remonta ao modelo de racionalidade da medicina hipocrática cuja lógica está em prevenir a doença antecipando-se a ela segundo o conhecimento de sua história natural. Estamos falando de uma "medicina do espírito" (expressão de Antoine Le Camus, médico contemporâneo de Rousseau) na seguinte passagem da Carta: "Tudo o que a sabedoria humana pode fazer é prevenir as mudanças, impedir de longe tudo o que as traz; mas, assim que as toleramos e as autorizamos, raras vezes estamos no controle de seus efeitos e nunca podemos ter a certeza de controlá-los" (ROUSSEAU, 2020, p. 430). De todo modo, não obstante o fato de tal interpretação da Carta recuperar em meio aos antigos o modelo da medicina expectante e da "medicina da alma" das Tusculanas de Cícero, a cena em geral vai além da catarse da Poética e propõe uma teoria dos auditórios mais complexa do que aquela encontrada em Aristóteles, o que nos leva a compreender afirmações da Carta como "o teatro purga as paixões que não temos e fomenta as que temos" (ROUSSEAU, 2020, p. 376). Tudo se passa como se, em Rousseau, os efeitos do teatro fossem examinados à maneira do médico que avalia todos os efeitos da intervenção sobre o doente, de modo a ponderar judiciosamente entre o estado idealmente almejado e as condições particulares do auditório. Em última instância, são essas condições que correspondem ao fato inexorável que faz da medicina uma arte difícil: o mesmo pharmakon

\begin{tabular}{|c|c|c|c|c|}
\hline Q Rovista Oialectus & Ano 9 & n. 17 & Maio - Agosto 2020 & p.271-292 \\
\hline
\end{tabular}


capaz de curar um paciente robusto pode matar um outro que se encontre fraco demais para suportar os efeitos colaterais do tratamento, cabendo ao médico adequar sua intervenção para cada caso.

Contudo, até aí não vemos nada de novo em relação à arte médica segundo Hipócrates. O detalhe inovador passa pelo deslocamento epistemológico, que transforma a história da doença em história do doente, ou seja, em vez de referenciar o saber médico num determinismo orientado pela evolução da causa dos males em geral, o novo modelo de racionalidade médica se volta para a evolução dos efeitos da doença num paciente singular, bem ao gosto dos empiristas da época. Assim, espera-se do diagnóstico nessa nova perspectiva que sejam considerados com prudência não apenas os benefícios futuros do remédio, mas também os sucessivos estados de saúde do paciente na evolução do tratamento que, como qualquer fenômeno inscrito na história, pode mudar de acordo com fatos contingentes. Seria um retorno à antiga lógica dos tribunais de casuística do direito romano (ali o princípio era que o fato precede a lei, e não o inverso), se o que estivesse em questão não fosse o conceito de histórias particulares nas quais as cadeias de causalidade existem, mas são tão complexas que dificilmente podem ser representadas através de modelos científicos simples (diga-se de passagem que, não por acaso, Rousseau tinha as Vidas de Plutarco como paradigma nesse ponto). Na perspectiva da história, a ordem civil é constituída por "um concurso de causas gerais e particulares" (ROUSSEAU, 2020, p. 376), e jamais poderia ser descrita como um caos, pois, se fosse um caos, não poderíamos falar em leis que presidem as histórias particulares e, por conseguinte, não haveria uma "ciência do homem" no sentido forte da palavra ciência.

Em suma, a perspectiva da relação entre teatro e moral da Carta a d'Alembert nos esclarece que, em Emílio, a arte da educação não visa produzir uma inclinação virtuosa na criança, mas tão somente reforçar a virtude que já existe por natureza e prevenir o desenvolvimento de vícios que inevitavelmente surgirão, o que nos leva a reconhecer, por um lado, a importância do dado antropológico da bondade natural, e por outro, a necessidade da metodologia "negativa" na pedagogia de Rousseau. Dito de outro modo, a missão do educador de Emílio não é configurar um arranjo das paixões que pudesse produzir necessariamente atos virtuosos, pois para tanto seria necessário acreditar nos poderes da arte sobre os costumes, como era o caso de d'Alembert; em vez disso, Rousseau admite uma hipótese mais fraca sobre a reforma moral e concede à arte o mero poder de acentuar as

\begin{tabular}{|c|c|c|c|c|}
\hline Q Rovista Oialectus & Ano 9 & n. 17 & Maio - Agosto 2020 & p.271-292 \\
\hline
\end{tabular}


tendências passionais que já existem, ponderando que até mesmo isso pode se mostrar impossível na prática. Quanto aos aspectos sociológicos da questão, se pudermos falar em um modelo teatral de educação pública, diríamos que se trata de formar a identidade moral de um povo acentuando seus traços passionais já existentes: “o efeito geral do espetáculo é reforçar o caráter nacional, aumentar as inclinações naturais e dar uma nova energia a todas as paixões" (ROUSSEAU, 2020, p. 374). Isso nos permitiria recorrer à Carta a d'Alembert com o intuito de examinar a questão do amor à pátria nas Considerações sobre o governo da Polônia, em particular, o capítulo sobre a educação dos poloneses. E, de fato, tal abordagem seria plausível, pois as Considerações são repletas de cenas teatrais que lembram a educação de Emílio. Entretanto, para não nos alongarmos demais, trataremos esse assunto em outra oportunidade.

Passemos agora aos desdobramentos do modelo dos espetáculos no sistema moral de Emílio. A sequência de argumentos apresentada no restante desse artigo é basicamente - e com poucas modificações - a mesmo do capítulo sobre a "ordem das paixões" em meu livro Educação e Filosofia no Emílio de Rousseau, que será publicado em breve pela Editora Unifesp.

\section{O lugar do sofrimento no teatro pedagógico de Emílio}

Rousseau concebe a cena pedagógica na perspectiva abrangente da "cena em geral", de modo a transpor para o teatro educativo de Emílio a reflexão sobre o teatro apresentada na Carta a d'Alembert. Em ambos os casos, no tocante ao suposto poder da arte sobre a moral, o genebrino se baseia num modelo de "cena" bem mais modesto que o modelo geral defendido por d'Alembert. O método da "educação negativa" de Emílio, cujo princípio está em ser uma educação menos propositiva em discursos e mais profilática quanto aos fatos que podem ameaçar a ordem moral, seria, do ponto de vista das faculdades, uma transposição do modelo da crítica aos espetáculos teatrais para o registro da arte da educação. A seguinte afirmação que lemos na Carta poderia muito bem aparecer em algum momento do livro IV de Emílio (como quando o Vigário saboiano afirma que a verdade está nas coisas e não em nosso juízo ${ }^{10}$ ): “o princípio do interesse que nos prende ao que é honesto e nos inspira aversão ao mal encontra-se em nós, e não nas peças. Não há arte que possa produzir esse interesse, mas

10 "As coisas! as coisas! Nunca repetirei bastante que damos poder demais às palavras; com nossa educação tagarela, fazemos apenas tagarelas" (ROUSSEAU, 1969, p. 447).

\begin{tabular}{|l|l|l|l|l|}
\hline Rovita Dialectus & Ano 9 & n. 17 & Maio-Agosto 2020 & p.271-292 \\
\hline
\end{tabular}


dele apenas pode se prevalecer" (ROUSSEAU, 2020, p. 378).

Todavia, é preciso observar uma mudança com relação às cenas anteriores à adolescência. Em todas as peças pedagógicas até os quinze anos, Emílio é ator; sendo o objeto central do espetáculo, tudo diz respeito ao eu absoluto do aluno. Isso está de acordo com a fase de desenvolvimento cognitivo: até esse momento, Emílio é governado pelo amor de si mesmo, e por isso, só conhece o próprio eu; porém, na passagem para o livro IV, ou seja, na entrada na adolescência, tornam-se necessárias as relações com a espécie, uma vez que é preciso desnaturar o eu, metamorfoseando-o num eu relativo aos outros. Emílio precisa conhecer os outros, e para isso, passará a observá-los em vez de ser observado. Daí se explica a mudança da cena do aluno, que muda da condição de ator para a de observador, tendo como paixão própria nada menos que... o amor-próprio! Donde se justifica também a recomendação do educador para que aos jovens sejam oferecidos "espetáculos que os cativem, e não espetáculos que os excitem" (ROUSSEAU, 1969, p. 517), de tal maneira que os progressos do espírito encontrem uma rota segura: "despistai sua imaginação nascente com objetos que, longe de pôr fogo em seus sentidos, reprimam sua atividade [...] mostrai-lhes apenas quadros tocantes, mas modestos, que os comovam sem os seduzir e alimentem sua sensibilidade sem lhes perturbar os sentidos" (ROUSSEAU, 1969, p. 517). O resultado dessas observações é um painel mental comparativo onde o próprio Emílio vislumbra uma escala de estima correspondente aos diferentes graus de interesse que sente por cada um dos homens observados. A diferença entre a estima e o juízo moral é que o juízo determina cada grau do painel de julgamentos segundo regras racionais contrabalançadas por assentimentos da consciência, ao passo que a estima o faz menos pela razão do que pelo móbile natural denominado "sentimento interior". ${ }^{11}$ As cenas da estima necessariamente precedem as cenas do juízo, por assim dizer. Veremos a seguir que a armação de todo esse espetáculo pedagógico envolvendo as faculdades da criança (e sobretudo sua faculdade do juízo moral) se sustenta por uma única viga-mestra, a saber, o sofrimento bem regrado.

O que vimos até aqui nos ajuda a perceber que a relação entre o movimento das paixões e a observação do mundo humano é absolutamente fulcral na pedagogia de Rousseau. É preciso que, ao observar os outros, Emílio sofra um abrandamento das paixões, e não estímulos. É preciso que as paixões permaneçam circunscritas ao domínio da estima natural,

11 Sobre o tema do "sentimento interior", ver meu artigo "Consciência e sentimento no Emílio de Rousseau" (KAWAUCHE, 2020).

\begin{tabular}{|l|l|l|l|l|}
\hline Rovita Dialectus & Ano 9 & n. 17 & Maio-Agosto 2020 & p.271-292 \\
\hline
\end{tabular}


sem se deixarem levar pelos excessos muitas vezes inevitáveis da estima pública e das opiniões preconceituosas. A chave que decifra o enigma é o sofrimento e, correlativamente, todas as paixões a ele relacionadas. As experiências em que Emílio é exposto a cenas de horror funcionam como extintores que apagam o fogo da imaginação, principal responsável por mobilizar as paixões em busca de prazer o tempo todo. Eis o sentido da expressão "freio das inclinações" que nosso autor utiliza para se referir à regulação das paixões pelas próprias paixões (ROUSSEAU, 1969, p. 494). Essas observações do mundo dos homens servem para sensibilizar o jovem com relação ao sofrimento alheio decorrente de causas naturais, como as misérias da vida, as doenças e, sobretudo, a morte. Uma cena como a do jovem militar levado pelo pai a um hospital de sífilis, por exemplo, é bastante eficaz para atenuar o fogo dos sentidos do adolescente que começa a descobrir os prazeres das relações com as mulheres: “Condenado por sua condição a passar sua juventude em quartéis, preferiu suportar todas as zombarias de seus camaradas a imitar sua libertinagem" (ROUSSEAU, 1969, p. 518). Contudo, essa sensibilização deve ocorrer com parcimônia por parte do educador, pois observações desse tipo em excesso podem levar o observador a se tornar insensível.

[...] Não se trata de tornar vosso aluno um enfermeiro, um irmão de caridade, de afligir seus olhares com objetos de dor e sofrimento contínuos, de levá-lo de doente em doente, de hospital em hospital, e da Grève às prisões; devemos comovê-lo, e não endurecê-lo, pela visão das misérias humanas. Impressionados durante muito tempo pelos mesmos espetáculos, deixamos de sentir suas impressões; o hábito acostuma a tudo; o que vemos demais já não imaginamos, e é somente a imaginação que nos faz sentir os males dos outros: é assim que, de tanto verem morrer e sofrer, os padres e os médicos tornam-se impiedosos. Conheça, portanto, vosso aluno a sorte do homem e as misérias de seus semelhantes; não seja, porém, com demasiada frequência testemunha delas. (ROUSSEAU, 1969, p. 517) $)^{12}$.

Nessa passagem, é importante notar a recomendação de que o recurso dos espetáculos seja administrado com muita sobriedade e comedidamente, tendo como paradigma empírico a série observável dos efeitos do hábito sobre o comportamento. A perspectiva é a de uma história natural do vício, por assim dizer, e a crítica para a administração dos espetáculos é semelhante àquela que vimos na Carta a d'Alembert. $\mathrm{O}$ detalhe notável é que, no Emílio, Rousseau presta mais atenção nos efeitos que causam desprazer no espectador. Nunca é demais lembrar da seguinte passagem que traduz com

12 A Grève era uma praça em Paris onde, durante o Antigo Regime, desempregados ofereciam-se para trabalho. Era na Grève também que aconteciam os suplícios públicos e as penas capitais. Não nos surpreende que a primeira decapitação na guilhotina da Revolução Francesa tenha ocorrido ali. A referida praça localizava-se

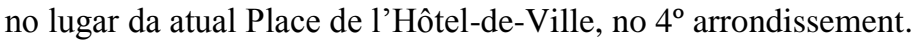

\begin{tabular}{|l|l|l|l|l|}
\hline Rovista Dialectus & Ano 9 & n. 17 & Maio-Agosto 2020 & p.271-292 \\
\hline
\end{tabular}


clareza impressionante o caráter negativo da educação para a felicidade de Emílio:

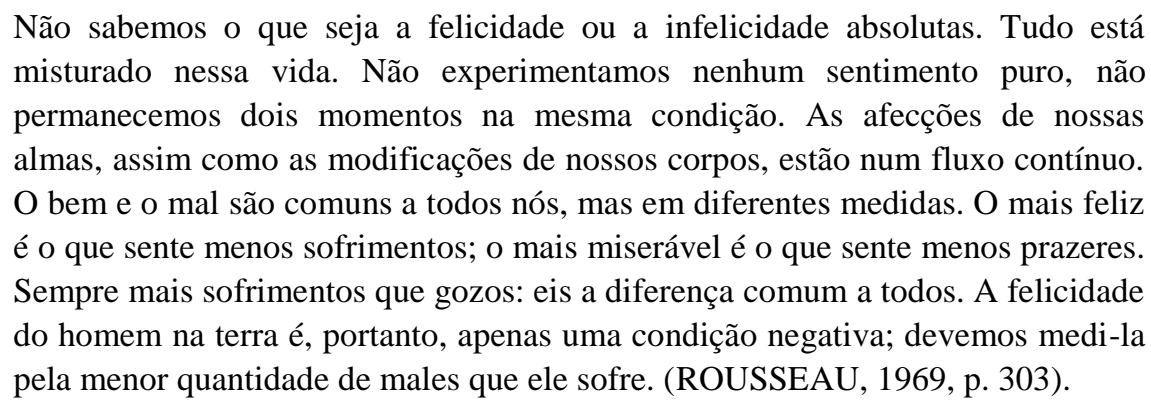

Se as cenas de dor e sofrimento forem contínuas, a sensibilidade do jovem ficará embotada pelo costume, e ele acabará se tornando insensível e impiedoso (Rousseau dá como exemplos os médicos e os padres). A justa medida entre os sentimentos desregrados e os comportamentos automáticos deve ser buscada pelo educador também no caso dos espetáculos chocantes. A liberdade deve ser "bem regrada" (ROUSSEAU, 1969, p. 321), mas não regrada em excesso, pois se assim fosse, a educação levaria à formação de uma máquina em vez de um ser moral (lembremos: no Emílio, as regras dizem respeito primeiro às paixões, e somente depois à razão). Um indivíduo livre, condicionado às regras de civilidade, não deve ser confundido com um autômato, isto é, um corpo artificial absolutamente desprovido de paixões; Rousseau é categórico quando define a liberdade humana tendo como parâmetros o poder e o prazer: "O homem verdadeiramente livre só quer o que pode e faz o que lhe agrada. Eis a minha máxima fundamental” (ROUSSEAU, 1969, p. 309, meus os itálicos). Ou seja, evita-se, por um lado, que o sofrimento seja obnubilado pelo gozo, e por outro, que o gozo regule o sofrimento (no modelo de Emílio, é o inverso que assegura a boa ordem das paixões). Em suma, a ideia norteadora do teatro pedagógico no qual Emílio será educado é a busca da felicidade por meio da moderação do sofrimento.

Consideremos agora outro aspecto problemático dessa pedagogia do espetáculo. Quanto mais observa os homens, mais Emílio se compara com eles, e a comparação excita o desejo de estar em primeiro lugar. A paixão do amor-próprio se consolida na medida em que Emílio compara-se com os outros e se habitua a preferir a si mesmo a despeito das relações com a espécie: "o primeiro olhar que lança sobre seus semelhantes leva-o a comparar-se com eles; e o primeiro sentimento que essa comparação excita nele é o de desejar o primeiro lugar" (ROUSSEAU, 1969, p. 523). Veja-se que, mais uma vez, o sofrimento aparece implicado nesse sistema moral em suas versões de frustração e ressentimento. Já vimos, no Discurso sobre a origem da desigualdade, que, se as paixões progredirem dessa maneira, a tendência

\begin{tabular}{|c|c|c|c|c|}
\hline Q Rovista Oialectus & Ano 9 & n. 17 & Maio - Agosto 2020 & p.271-292 \\
\hline
\end{tabular}


da história da sociedade é o desenvolvimento de desigualdades civis cada vez mais injustas que levam, ao fim e ao cabo, ao colapso das relações entre os homens. Assim, a pergunta que se coloca no Emílio é: como deve o educador intervir para dar uma outra direção ao amorpróprio? A resposta é dupla: recorrendo-se à amizade e ao ensino da história. No primeiro caso, Emílio lidará com o amor-próprio em relação aos próximos; no segundo, observará diferentes homens do passado movidos por paixões e, ao comparar suas ações com as deles, aprenderá a identificar em si mesmo os perigos das paixões em geral, e sobretudo, da paixão do amor-próprio: "depois de lhe ter mostrado os homens pelos acidentes comuns da espécie, é preciso agora mostrá-los a ele por suas diferenças"; e completa com menção à ideia de ordem, em torno da qual gira toda a reflexão exposta até agora: "Aqui surge a medida da desigualdade natural e civil, bem como o quadro de toda a ordem social" (ROUSSEAU, 1969, p. 524). Tanto no caso da amizade quanto no ensino da história, o "quadro das paixões" permanecerá moderado entre o desejo exacerbado de ser o primeiro e os sentimentos nocivos à ordem moral que necessariamente emergiriam por conta das frustrações e dos ressentimentos dos fracassos implicados no campo dessa espécie de "luta por reconhecimento". Neste artigo, será considerado apenas o recurso pedagógico da amizade, pois a exposição abrangente sobre o ensino da história no Emílio encontra-se no livro Ilustração e história, de Maria das Graças de Souza (2001) ${ }^{13}$. Contudo, antes de entrarmos na discussão sobre a amizade, é preciso dizer algo acerca do sentimento que a antecede, isto é, o apego.

\section{A amizade como remédio regulador do amor-próprio}

O apego decorre de uma expansão do amor natural do bebê em relação aos seus cuidadores: "O primeiro sentimento de uma criança é amar a si mesma; o segundo, que deriva do primeiro, é amar aos que dela se aproximam, pois, no estado de fraqueza em que se encontra, ela não conhece ninguém a não ser pela assistência e pelos cuidados que recebe" (ROUSSEAU, 1969, p. 492). Assim como o bebê, Emílio expande seu sentimento de amor a

13 No tratamento das paixões de Emílio, os amigos e os livros de história são remédios complementares e, por isso, não podem ser administrados separadamente. É preciso, portanto, que o aluno olhe "de perto" e "de longe". Nas relações de amizade, Emílio conhece os homens de perto e compara-se do ponto de vista das semelhanças; mas para observar as diferenças, é preciso que o olhar de Emílio se afaste do objeto observado de tal maneira a abrir-se para a variedade de tipos humanos. Daí a necessidade do espetáculo da história, cuja função é permitir que o aluno conheça a fundo a natureza humana, porém, sem que suas paixões do observador atrapalhem a observação e o desviem da rota da virtude. Haveria mais a comentar nesse quesito, mas tudo já foi explicado no capítulo sobre Rousseau do livro Ilustração e história (SOUZA, 2001).

\begin{tabular}{|l|l|l|l|l|}
\hline Q Rovista Dialectus & Ano 9 & n. 17 & Maio - Agosto 2020 & p.271-292 \\
\hline
\end{tabular}


fim de incluir os outros que se encontram dentro de seu campo de observação: inicialmente, trata-se de mero apego, mas à medida que o apego vai sendo ordenado pelo hábito engendrado no seio da própria relação, adquire duas formas possíveis: o desejo de possuir o outro e o sentimento de amizade. O bebê observa todos aqueles que cuidam dele e, de acordo com o progresso dos afetos, sente apego por essas pessoas: “Toda criança se apega a sua ama: Rômulo devia se apegar à loba que o amamentou. De início, esse apego é puramente maquinal. O que favorece o bem-estar de um indivíduo atrai-o; o que o prejudica repele-o; isso não passa de um instinto cego" (ROUSSEAU, 1969, p. 492). O apego, enquanto instinto (pensemos nos impulsos do homem natural do Segundo Discurso), pode até funcionar bem no âmbito da natureza; todavia, seus efeitos são nocivos quando os comportamentos devem se adequar às relações que constituem a ordem social: o adolescente que, por conta de seus desejos, se apega aos adultos próximos, acaba se tornando dependente dos outros e, do ponto de vista das relações do indivíduo, escravo das próprias paixões. ${ }^{14}$ No Emílio, Rousseau prescreve uma fórmula para combater o apego, que é o hábito da virtude: “As amas, as mães apegam-se às crianças pelos cuidados que lhes prestam; o exercício das virtudes sociais leva ao fundo dos corações o amor à humanidade: é praticando o bem que nos tornamos bons; não conheço nenhuma prática mais segura" (ROUSSEAU, 1969, pp. 543-544). O indivíduo apegado aos outros tem paixões desordenadas; é preciso colocá-las em concerto se o educador pretende conciliar de fato a ordem das paixões e a ordem civil. Na farmácia de Emílio, recorre-se agora à amizade:

O apego pode dispensar a reciprocidade; a amizade nunca. Esta é uma troca, um contrato como os outros; mas é o mais santo de todos. A palavra amigo não tem outro correlativo senão ela própria. Todo homem que não é o amigo de seu amigo é certamente um patife, pois é somente retribuindo ou fingindo retribuir a amizade que podemos obtê-la. (ROUSSEAU, 1969, pp. 520-521, nota).

A amizade é o remédio que fomenta a reciprocidade nas trocas afetivas e previne a dependência em relação ao outro por quem se sente apego. $\mathrm{O}$ amigo é o outro de uma relação pautada pela igualdade entre indivíduos que, sem deixar de serem egoístas, ainda assim encontram vantagem na reciprocidade de satisfação de seus desejos. A amizade é, nesses termos, um modelo de relação sem dependência recíproca, verdadeira metáfora para a

14 Vale a pena citar a crítica ao apego no livro II de Emílio que vem à reboque na crítica aos vícios causados pela previdência excessiva: “[...] apegamo-nos a tudo, agarramo-nos a tudo; os tempos, os lugares, os homens, as coisas, tudo o que é, tudo o que será importa a cada um de nós mesmos. Cada qual se estende, por assim dizer, sobre a terra inteira e se torna sensível sobre toda essa grande superfície. É de se admirar que nossos males se multipliquem em todos os pontos por onde podem nos ferir? Quantos príncipes se desolam com a perda de um país que nunca viram!" (ROUSSEAU, 1969, p. 307).

\begin{tabular}{|l|l|l|l|l|}
\hline Rovista Dialectus & Ano 9 & n. 17 & Maio-Agosto 2020 & p.271-292 \\
\hline
\end{tabular}


isonomia. Pensar numa ordem justa a partir do modelo da relação de amizade é, aos olhos de Rousseau, pensar em trocas afetivas que estabelecem relações equitativas entre seres semelhantes. Podemos daí dizer que as brincadeiras com os amigos são espetáculos que ordenam os afetos dos adolescentes porque a estrutura mesma da cena das brincadeiras entre amigos é constituída segundo as verdadeiras relações da espécie, são "jogos" de sociabilidade nos quais o alvo é o estabelecimento de relações isonômicas entre indivíduos que se comparam e julgam a si mesmos como reciprocamente iguais. Esse esquema nos remete aos movimentos mais espontâneos no desenvolvimento das crianças:

\begin{abstract}
Não imagino nada cujo gosto, ou até mesmo o furor, não possamos insuflar, com um pouco de habilidade, nas crianças, e isso, sem vaidade, sem emulação, sem inveja. Bastam sua vivacidade, seu espírito imitador e, sobretudo, sua alegria natural, instrumento de eficácia segura, mas do qual nenhum preceptor se lembrou. Em todos os jogos em que estão bem persuadidas de que se trata apenas de jogo, elas sofrem sem se queixar, rindo mesmo, o que não sofreriam nunca de outro modo sem derramar torrentes de lágrimas. (ROUSSEAU, 1969, p. 377).
\end{abstract}

Antes que o apego se transforme em desejo sexual, Emílio encontra uma versão amena do amor que o afeta, qual seja, a amizade: "O primeiro sentimento de que um jovem cuidadosamente educado é suscetível não é o amor, e sim a amizade. O primeiro ato de sua imaginação nascente é ensinar-lhe que tem semelhantes, e a espécie afeta-o antes do sexo" (ROUSSEAU, 1969, p. 502). Rousseau denomina o sentimento que surge nessa nova ordem dos afetos com a palavra-chave desse artigo: reconhecimento. $\mathrm{O}$ reconhecimento do outro como amigo se sobrepõe ao apego de modo análogo à liberdade civil que se sobrepõe à liberdade natural na instituição da ordem social; tanto no Contrato quanto no Emílio, o efeito salutar dessa moral primitiva que antecipa os sentimentos de sociabilidade consiste em impedir os efeitos nocivos precoces das comparações operadas pelo amor-próprio.

A amizade, evidentemente, não anula o jogo de interesses; estes, por força das próprias relações entre os amigos, podem eventualmente degenerar em abusos: La Rochefoucauld, cujas máximas sobre o amor-próprio repercutem em todo o período das Luzes francesas, diria que a amizade não passa de um arranjo recíproco de interesses. ${ }^{15}$ Mas, a despeito do risco, esse arranjo de interesses recíprocos é bem visto por Rousseau, pois, ainda que a amizade seja inseparável dos interesses, a ordem moral dos amigos é diferente daquela fundada na dependência entre os semelhantes (uma ordem de senhores e escravos) tal como

15 No parágrafo 83 das Réflexions ou Sentences de maximes morales: “O que os homens nomearam amizade é apenas uma sociedade, um arranjo recíproco de interesses, uma troca de bons ofícios. Enfim, é apenas um comércio no qual o amor-próprio propõe sempre algo a ganhar.” (LA ROCHEFOUCAULD, 2007, p. 26).

\begin{tabular}{|l|l|l|l|l|}
\hline Rovista Dialectus & Ano 9 & n. 17 & Maio-Agosto 2020 & p.271-292 \\
\hline
\end{tabular}


no quadro da sociedade retratada no Discurso sobre a desigualdade. No Emílio, o reconhecimento entre amigos é algo próximo dos sentimentos naturais e, por isso mesmo, não afronta a equidade das estimas recíprocas, ao passo que no Discurso sobre a desigualdade, os interesses dizem respeito a relações de dependência que, direta ou indiretamente, giram em torno da opinião pública e dos preconceitos. Com o progresso da estima, será preciso o recurso a outros remédios para a formação de um juízo moral que possa se coadunar com a equidade de interesses: na Profissão de fé do vigário saboiano, o reconhecimento se manifestará na forma de consciência moral. Assim como a estima é o embrião do juízo moral, analogamente o reconhecimento é, por assim dizer, o embrião da consciência moral.

\begin{abstract}
Se, portanto, o reconhecimento é um sentimento natural, e se não destruirdes seu efeito por vossa culpa, ficai certo de que vosso aluno, começando a perceber o valor de vossos cuidados, a eles será sensível conquanto não os tenhais vós mesmo negociado; vossos cuidados produzirão no coração dele uma autoridade que nada poderá destruir. [...] Jamais eu quis que lhe dissessem que o que fazem é para seu bem antes que estivesse em condição de entender isso; nesse discurso, ele veria apenas vossa dependência e vos encararia como seu criado. Mas agora que começa a sentir o que é amar, sente também que doce laço pode unir um homem àquilo que ele ama; e no zelo com que vos ocupais dele sem cessar, ele vê menos o apego de um escravo do que a afeição de um amigo. Ora, nada tem tanto peso no coração humano quanto a voz da amizade bem reconhecida, pois, bem sabemos que ela só fala a favor de nosso interesse. Podemos acreditar que um amigo se engane, mas não que queira nos enganar. Algumas vezes resistimos a seus conselhos, mas nunca os desprezamos. (ROUSSEAU, 1969, p. 522).
\end{abstract}

Cabe lembrar que, quando nos referimos ao reconhecimento dos laços de amizade, estamos ainda no âmbito dos sentimentos naturais; o aluno é sensível ao espetáculo da amizade e faz bom uso das comparações dos diversos sentimentos que experimenta, criando assim um parâmetro autônomo de seus juízos independentes, ou seja, uma "autoridade que nada poderá destruir" instalada em seu próprio "coração": "nada tem tanto peso para o coração humano quanto a voz da amizade reconhecida". Neste momento da educação de Emílio, a estima ainda não sucumbiu à opinião; um amigo reconhecido enquanto tal não pode ser um adversário como os indivíduos do estado de guerra de Hobbes, que são descritos como competitivos e desconfiados uns dos outros (ver cap. 13 do Leviatã). Diferentemente do homem-criança de Hobbes, a criança de Rousseau é movida mais pelo amor do que pelo cálculo racional que prevê os males futuros (veja-se aí mais uma vez o esquema do "quadro das paixões" da Carta) e, portanto, confia no amigo e pode pactuar com ele: "Podemos acreditar que um amigo se engana, mas não que nos queira enganar”. É por estarmos na iminência da entrada no estado de vícios que o amor-próprio não pode ser considerado apenas

\begin{tabular}{|c|c|c|c|c|}
\hline Q Rovista Oialectus & Ano 9 & n. 17 & Maio - Agosto 2020 & p.271-292 \\
\hline
\end{tabular}


por seus efeitos negativos. Assim como a imaginação, ele pode mostrar-se benéfico ou nocivo, dependendo das circunstâncias. É no sentido de um sentimento natural que se expande (como reconhecimento entre amigos que será transformado em juízo moral) que podemos entender Rousseau quando ele diz: "Estendamos o amor-próprio aos outros seres; transformálo-emos em virtude, e não existe coração de homem em que essa virtude não tenha raiz" (ROUSSEAU, 1969, p. 547). A ideia de expansão que Pierre Burgelin expõe em La Philosophie de l'existence de Rousseau (1952) é a chave para a leitura desse texto e, de modo geral, da teoria do reconhecimento exposta neste artigo. A imagem do organismo que cresce é recorrente na obra de Rousseau: não apenas o corpo da criança na história de Emílio, mas também os corpos políticos que se expandem e acabam entrando em conflito nas relações internacionais, como lemos nos fragmentos sobre o estado de guerra (ver BECKER, 2011) ou no próprio Contrato social. Mas o tema da expansão dos sentimentos, que no Brasil é comentado melhor nos trabalhos de Marisa Vento (ver, em particular, VENTO, 2012), será assunto para um novo artigo.

$$
* * *
$$

Para finalizar o nosso percurso - e talvez extrapolando um pouco a discussão no Emílio -, uma palavra sobre a relação entre amizade e casamento.

Por favorecer a igualdade nas relações da espécie, a amizade pode ser usada como um remédio na prevenção dos efeitos funestos ligados ao amor-próprio. Mas sabemos que as amizades não bastam na puberdade. A força das paixões sexuais é imensa e requer o uso de remédios mais poderosos. Se Emílio começasse a namorar neste momento, ele acabaria fazendo de sua companheira um objeto de satisfação de seus apetites, ou seja, uma escrava, pois sua razão ainda não é forte o bastante para conter a avalanche dos impulsos sexuais nascentes. Lembremos que, ao descrever a amizade como primeiro sentimento, Rousseau nota que "a espécie afeta-o antes do sexo" (ROUSSEAU, 1969, p. 502). Mas essa inversão da ordem natural das paixões não decorre, obviamente, das cadeias de necessidade da ordem social, e sim da arte do educador. O encontro entre Emílio e Sofia deve, por isso mesmo, ser adiado mais um pouco por interlúdios entre as cenas maiores, pois os sentimentos de benevolência, ainda fracos e tímidos, sucumbiriam diante das paixões maléficas do amorpróprio que imperam no corpo (veja-se que, no livro V, a viagem de Emílio que faz Sofia aguardar pela volta do noivo é um intermezzo que faz as vezes de cena maior).

\begin{tabular}{|c|c|c|c|c|}
\hline Qovista Dialectus & Ano 9 & n. 17 & Maio - Agosto 2020 & p.271-292 \\
\hline
\end{tabular}


Entende-se daí que é por uma questão de ordem que Rousseau não pode conceber a gênese das relações sociais condicionada à ideia de família: nas relações de família, prevaleceria, no atual estágio da história de Emílio, o desejo de dominação do homem sobre a mulher e do pai sobre os filhos. Lembremos que a ordenação no Emílio é sempre um processo lento, gradual e quase imperceptível, semelhante à reação química da fermentação (uma bela metáfora seria a da imagem da boa levedura que transmuta os sentimentos de amizade em sentimentos de amor, bem como a metáfora inversa do mauvais levain que seria responsável pela putrefação dos corpos morais). No âmbito da pedagogia rousseauniana, antecipar a instituição da família na marcha da natureza implica em instituir uma relação de dominação por princípio, na qual a mulher seria reduzida à condição de mero objeto de prazer do homem. Se assim acontecesse, as relações morais estariam forçosamente corrompidas desse momento em diante. Por outro lado, sabemos que as paixões sexuais são constitutivas da ordem civil: o "segundo nascimento" é "para o sexo"; sem a união com Sofia, Emílio não poderá sentir as relações do homem em sua plenitude, pois afinal, "eis quando o homem nasce verdadeiramente para a vida, e quando nada de humano lhe é estranho" (ROUSSEAU, 1969, p. 489). É preciso lembrar que, do ponto de vista da boa ordem, o percurso da educação de Emílio termina necessariamente no casamento.

De modo geral, a família é um elemento incontornável nas teorias sociais, até mesmo naquelas que, à maneira de Rousseau no Discurso sobre a desigualdade, recusam considerá-la o fundamento da ordem civil. Não é despropositado que, no Emílio, a teoria do reconhecimento estabeleça o momento adequado da emergência da família. Para Rousseau, a educação segundo a natureza observa a seguinte sequência no ordenamento da sociabilidade: primeiro os pais, depois os amigos e, somente em último lugar, os amores. Ora, não veríamos nessa ordem "sagrada" nada além de santimônia se não fosse um detalhe: Rousseau zomba das fábulas com final feliz. Se, por um lado, é preciso reconhecer que as paixões naturais surgem e se desenvolvem no seio da família, por outro, isso não significa que, para Rousseau, a família construída pelo amor do casal heterossexual represente o fundamento feliz da sociedade. $\mathrm{O}$ amor entre Emílio e Sofia não valeria absolutamente nada se ele não fosse construído a partir do princípio da ordem das paixões, e tanto isso é verdade que Rousseau não explica sua desesperança no mundo civil falando, como fazem os beatos, em falta de amor nos casamentos - sua crítica tem o alvo muito exato da desordem sistêmica envolvendo instituições e sentimentos; desordem esta que, semelhante a uma neoplasia maligna, afeta os

\begin{tabular}{|c|c|c|c|c|}
\hline Q Rovista Oialectus & Ano 9 & n. 17 & Maio - Agosto 2020 & p.271-292 \\
\hline
\end{tabular}


membros do corpo coletivo reforçando as inclinações viciosas que perpassam o ordenamento social (Honneth utilizaria aqui o conceito de "patologias do social").

Sendo portanto inegável a relação entre a desordem da sociedade e a desordem das histórias de amor particulares, podemos encerrar este trabalho com a seguinte conclusão: embora o amor na história de Emílio e Sofia seja insuficiente para reforçar a boa ordem da sociedade de modo perene, ainda assim é esse amor que, de alguma maneira, está ligado aos dispositivos passionais que adiam as catástrofes que inevitavelmente nos conduzirão ao fim do mundo. Diferentemente de Locke, a família segundo Rousseau não é o ponto de partida para a instituição da sociedade, mas, isto sim, a sua consequência mais sofisticada, ou quiçá, impossível. O amor do casal seria, nesse sentido, um efeito da sociedade bem ordenada, muito embora possamos compreender que, semelhante a um sistema retroalimentado, a sociedade também se beneficia das paixões particulares bem ordenadas. Ainda que não possamos evitar o fim, podemos ao menos postergá-lo limitando o nosso sofrimento diário à sua justa medida e usufruindo daquilo que é possível usufruir na ordem atual em que nos encontramos. Seria então nas "cenas de um casamento", para lembrarmos do filme de Ingmar Bergman (Scener ur ett äktenskap, Suécia, 1973), que residiria nossa frágil esperança?

\section{REFERÊNCIAS}

ARCO JR., M. D. B. A origem da alteração e a alteração de origem: antropologias de Rousseau. Tese de Doutorado. São Paulo, Universidade de São Paulo, Departamento de Filosofia, 2018.

BECKER, E. Apresentação dos Princípios do direito da guerra e dos Fragmentos sobre a guerra de Rousseau. Trans/Form/Ação (Unesp-Marília), v. 34, n. 1, 2011.

BURGEliN, P. La Philosophie de l'existence de J.-J. Rousseau. Paris: Presses Universitaires de France, 1952.

CICERO, M. T. Tusculan Disputations. Trad. J. E. King. Cambridge: Harvard University Press, 1927 (Loeb Classical Library).

CONDILlAC, E. B. Tratado das sensações. Trad. Denise Bottmann. Campinas: Ed. Unicamp, 1993.

D’ALEMBERT, J. Genebra. In: PIMENTA, P. P.; SOUZA, M. G. (Org.). Enciclopédia, ou Dicionário razoado das ciências, das artes e dos ofícios, v. 4: Política. São Paulo: Edunesp, 2015.

FRANCISCO, M. F. S. Rousseau e a questão das educações pública e doméstica. Cadernos de Ética e Filosofia Política (USP), n. 16, 2010.

HOBBES, T. Leviatã. Trad. João Paulo Monteiro e Maria Beatriz Nizza da Silva. São Paulo:

\begin{tabular}{|c|c|c|c|c|}
\hline Qevista Dialectus & Ano 9 & n. 17 & Maio - Agosto 2020 & p.271-292 \\
\hline
\end{tabular}


Abril, 1974.

HONNETH, A. Abismos do reconhecimento: o legado sociofilosófico de Jean-Jacques Rousseau. Civitas (PUC-RS), Porto Alegre, v. 13, n. 3, 2013.

KAWAUCHE, T. Ordenar as paixões: reconhecimento e sociabilidade no Emílio de Rousseau - Primeira parte. Dialectus, Fortaleza, ano 8, n. 15, 2019. 2020.

Consciência e sentimento no Emílio de Rousseau. Discurso (USP), v. 50, n. 1,

LA ROCHEFOUCALD, F. Collected Maxims and Other Reflections. Oxford University Press, 2007.

LE CAMUS, A. Médecine de l'esprit. Paris, 1753.

LEITE, R. A. V. O teatro em Rousseau: entre o universal e o particular. Tese de Doutorado. Curitiba, Universidade Federal do Paraná, Departamento de Filosofia, 2018.

MATTOS, F. Teatro e amor-próprio. In: ROUSSEAU, J.-J. Carta a d'Alembert. Campinas, Ed. Unicamp, 1993.

PRADO JR., B. Gênese e estrutura dos espetáculos. Estudos Cebrap, São Paulo, n. 14, 1975.

ROUSSEAU, J.-J. Carta a D'Alembert sobre os espetáculos. In: Obras de Jean-Jacques Rousseau, v. I. Trad. Lourdes Santos Machado. Porto Alegre: Globo, 1958. 2 v.

Carta a D'Alembert. Trad. Roberto Leal Ferreira. Campinas: Ed. Unicamp, 1993.

Carta a D'Alembert sobre os espetáculos teatrais. Trad. Fabio Stieltjes Yasoshima. In: PIMENTA, P. P. (Org.). Rousseau: escritos sobre a política e as artes. São Paulo: Ubu, 2020.

Discours sur l'origine et les fondements de l'inégalité parmi les hommes. In: Euvres complètes, t. III. Paris: Gallimard, 1964 (Bibliothèque de la Pléiade).

Discurso sobre a origem e os fundamentos da desigualdade entre os homens. Trad. Maria Ermantina Galvão. São Paulo: Martins Fontes, 1993.

Émile, ou de l'éducation. In:

Euvres complètes, t. IV. Paris: Gallimard,

1969 (Bibliothèque de la Pléiade). [Todas as passagens traduzidas de Émile são de responsabilidade do autor do artigo.]

SALINAS FORTES, L. R. Dos jogos de teatro no pensamento pedagógico e político de Rousseau. Discurso (USP), São Paulo, n. 10, 1979.

Paradoxo do espetáculo: política e poética em Rousseau. São Paulo: Discurso, 1997 [baseado na tese de livre-docência defendida em 1983].

SOUZA, M. G. Ilustração e história: o pensamento sobre a história no Iluminismo francês. São Paulo: Discurso Editorial, 2001.

VENTO, M. A. O movimento de expansão e a generalização do interesse e da vontade. Cadernos de Ética e Filosofia Política (USP), São Paulo, v. 21, 2012.

\begin{tabular}{|c|c|c|c|c|}
\hline Rovista Dialectus & Ano 9 & n. 17 & Maio - Agosto 2020 & p.271-292 \\
\hline
\end{tabular}

